\title{
METASTATIC BREAST CARCINOMA WITH MULTIPLE OSTEOLYTIC LESIONS - A DIAGNOSTIC DILEMMA
}

\author{
L. Aruna1, P. Manimekhala², Shajia Rahman³ ${ }^{3}$ M. Lavanya4, D. Sumanth Kumar ${ }^{5}$
}

\section{HOW TO CITE THIS ARTICLE:}

L. Aruna, P. Manimekhala, Shajia Rahman, M. Lavanya, D. Sumanth Kumar."Metastatic Breast Carcinoma with Multiple Osteolytic Lesions - A Diagnostic Dilemma”. Journal of Evolution of Medical and Dental Sciences 2014; Vol. 3, Issue 02, January 13; Page: 322-325, DOI:10.14260/jemds/2014/1828

ABSTRACT: Bone is one of the common sites for distant metastasis from breast cancer. About 6\%$10 \%$ of breast carcinomas have already spread to distant sites at the time of initial diagnosis. Presence of bone metastasis affects patient's prognosis and the planning of treatment. We report a case of 32year old female who presented with a subtrochanteric fracture left femur and multiple osteolytic lesions throughout the axial skeleton leading to clinical suspicion of multiple myeloma. Hematological work up suggested a metastatic deposit. Subsequent detailed examination revealed a breast lump in right breast. On core biopsy it was diagnosed as duct cell carcinoma. This report addresses the role of bone marrow examination in arriving at a diagnosis in multiple osteolytic lesions which pose wide differential diagnoses.

KEYWORDS: Metastatic breast carcinoma, multiple osteolytic lesions, Bone marrow aspiration

INTRODUCTION: Breast cancer is most common cancer in women in many countries, including developing countries. In India breast cancer is the second most common cancer in women. Breast cancer is increasing both in young ( $11 \%$ per decade) and old women ( $16 \%$ per decade). It is estimated that 1, 00, $000-1,25,000$ patients are newly diagnosed to have breast cancer in India every year. Since 1990 the incidence has increased 1.5\% annually. ${ }^{1}$ Approximately $4-6 \%$ of breast cancers are metastatic at the time of diagnosis ${ }^{2}$. Bone is the most common site of distant metastasis and metastasis to bone are diagnosed in $30 \%-85 \%$ of patients with advanced breast cancer. ${ }^{3}$ Bone metastasis causes much of the morbidity and disability in patients with breast cancer.

CASE REPORT: A 32year old female presented to our hospital with difficulty on walking and pain in both hip regions, more on left side. On physical examination she had limited and painful movements of left hip joint. An initial X-ray of the pelvis showed a subtrochanteric fracture of left femur, along with multiple osteolytic lesions in the pelvis. X ray of spine and skull also showed multiple osteolytic lesions. MRI of pelvis and whole spine was done which also revealed multiple osteolytic lesion involving spine and pelvis, the differential diagnosis offered were multiple myeloma and metastasis.

In view of clinical suspicion of multiple myeloma a complete hemogram was done which was within normal limits. No abnormal cells were seen and there was no rouleaux formation and the blood picture was normocytic hypochromic. Urine for Bence jones proteins was negative, serum calcium was within normal limits $-8.4 \mathrm{mg} / \mathrm{dl}$, blood urea nitrogen was elevated to $60 \mathrm{mg} / \mathrm{dl}$, and serum creatinine was $2.2 \mathrm{mg} / \mathrm{dl}$. Serum protein electrophoresis was done and there was no M spike. As there was high suspicion of multiple myeloma bone marrow aspiration was done.

The aspiration yielded only scanty material and the smears showed few clusters of large pleomorphic round to oval cells with scant cytoplasm, round to oval nucleus with coarse chromatin and one or two prominent nucleoli. The cell block was prepared with the aspirate which also showed 
these similar cell clusters in a hemorrhagic background with no marrow elements. Based on the morphology, a possibility of metastatic deposits of carcinoma was given. Bone marrow biopsy was attempted but was unsuccessful. IHC was done on the cell block. The pleomorphic cells were positive for Pan CK suggesting a metastatic deposit of epithelial malignancy.

A detailed retrospective general examination revealed right breast mass of $1.2 \mathrm{cms}$ diameter in upper outer quadrant, firm in consistency with restricted mobility. A single right axillary lymph node was also palpable. Ultrasound of breast showed right breast mass measuring $1.6 \times 1.9 \mathrm{cms}$. with internal vascularity and axillary lymph node measuring 1.5 x $1.2 \mathrm{cms}$.

Fine needle aspiration of the right breast mass was suggestive of proliferative breast disease and from right axillary lymph node showed features consistent with reactive changes.

With a high degree of suspicion of metastatic carcinoma, a trucut biopsy of right breast mass was advised. Serum CA 15.3, which is a marker of metastatic breast carcinoma was also done which was highly elevated to $1806 \mathrm{U} / \mathrm{ml}$ (normal $<32 \mathrm{U} / \mathrm{ml}$ ). Histopathology of core biopsy showed pleomorphic ductal epithelial cells with hyperchromatic nuclei. IHC for P 63 was negative. With the above findings a diagnosis of invasive duct cell carcinoma was given. Patient was referred to regional cancer institute and presently receiving chemotherapy and is being followed up.

DISCUSSION: About 4-6\% of breast carcinomas present with metastases at the time of initial diagnosis of which bone is the most common site. ${ }^{4}$ Interactions between neoplastic cells and bone marrow-derived cells aid the metastatic process. There is a possibility that bone marrow serves as a 'sanctuary' to protect metastatic breast cancer cells. ${ }^{5}$

This protective environment may support the metastatic foci before they progress locally to form bony metastases or equally serve as a platform from which breast cancer cells can be stimulated locally or systemically to seed other organs or even re-seed the site of the original primary tumor. ${ }^{6}$

Bone metastases from breast carcinoma can present as blastic, osteolytic or mixed lesions. ${ }^{7}$ Purely osteolytic lesions can simulate the picture of multiple myeloma. Identification of etiology of osteolytic lesions may be further difficult if the breast mass is not the initial complaint at the time of presentation as it was in our case. Workup for anosteolytic lesion should first exclude the possibility of a multiple myeloma. M spike on serum protein electrophoresis and other biochemical parameters are useful tools to safely exclude the possibility of a multiple myeloma, but one should always remember that non secretory myeloma does not show a $\mathrm{M}$ spike.

A bone marrow aspiration along with IHC of cell block can be of great help in arriving at a diagnosis in such cases. When in doubt, serum CA 15.3 levels can be a useful marker in metastatic breast carcinoma ${ }^{8}(>30 \mathrm{u} / \mathrm{ml}$ indicates metastasis and poor prognosis). Numerous studies have indicated that CA15.3 is a reliable marker in breast carcinoma and correlates well with the disease stage. ${ }^{9}$ A similar case was reported in literature by Daniela Katz et, al. ${ }^{10}$ In our case serum CA 15.3 concentration correlated with the diagnosis given on bone marrow aspiration and helped us to locate the primary.

There are few cases reported in the literature which showed multiple myeloma in known case of breast carcinoma ${ }^{11,12}$. The present case clinically thought as multiple myeloma turned out to be metastatic deposits of breast carcinoma. 
CONCLUSION: The present case emphasizes that a thorough workup is necessary to come to a specific diagnosis in osteolytic lesions as a metastatic malignancy can mimic a multiple myeloma or a multiple myeloma can be camouflaged by metastatic deposit.

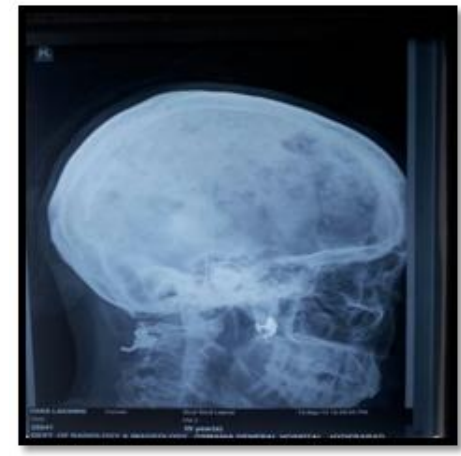

Fig.1: Multiple lytic lesion in skull Lateral view

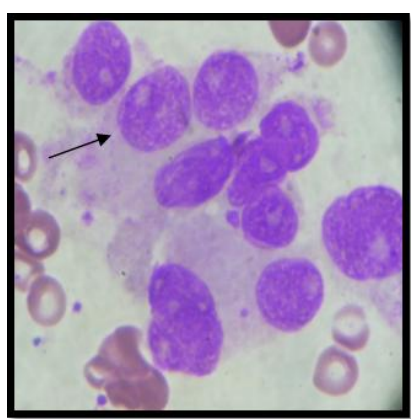

Fig. 3: Bone marrow aspiration showing clusters of pleomorphic cells with scant amount of cytoplasm coarse chromatin and prominent nucleoli

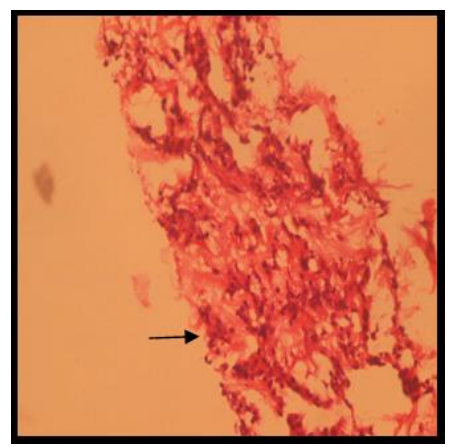

Fig. 5: Tru cut biopsy breast showing pleomorphic cells with hyperchromatic nuclei

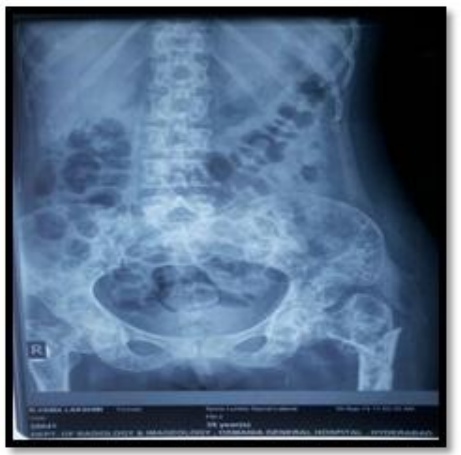

Fig.2: Lytic lesions in pelvis and left supratrochanteric fracture AP view

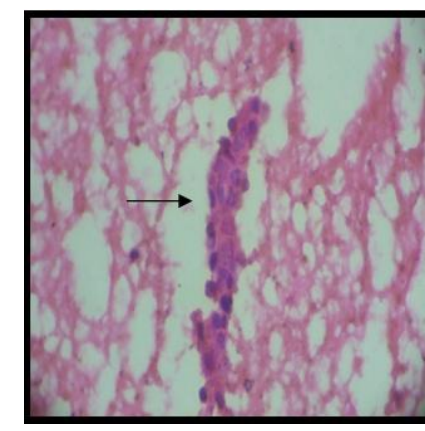

Fig. 4: Cell block showing pleomorphic cell clusters

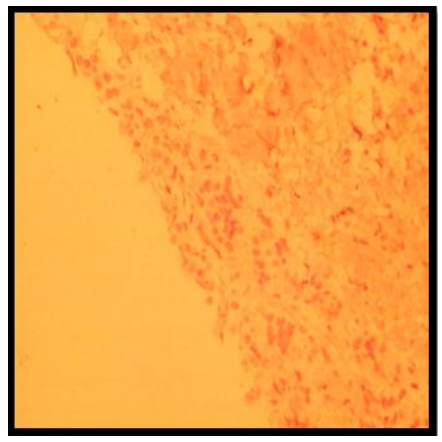

Fig. 6: IHC P63 negative

\section{REFERENCES:}

1. Takiar R, Nadayil D, Nandakumar A. Projections of number of cancer cases in India (20102020) by cancer groups. Asian Pac J Cancer Prev. 2010; 11(4):1045-9. 
2. F. Cardoso, L. Fallowfield, A. CostaM, Castiglione E. Senkus.Locally recurrent or metastatic breast cancer: ESMO Clinical Practice Guidelines for diagnosis, treatment and follow-up

3. E. F. Solomayer, I. J. Diel, G. C. Meyberg, C. Gollan, and G. Bastert, "Metastatic breast cancer: clinical course, prognosis and therapy related to the first site of metastasis, "Breast Cancer Res. Tr., vol. 59, no. 3, pp. 271-278, Feb. 2000.

4. Sheng-Fang Huang, and Kuo-Hsien Chian. Automatic Detection of Bone Metastasis in Vertebrae by Using CT Images. Proceedings of the World Congress on Engineering 2012 Vol IIWCE 2012, July 4 - 6, 2012,

5. Bussard KM, Gay CV, Mastro AM. The bone microenvironment in metastasis; what is special about bone? Cancer Metastasis Rev. 2008 Mar;27(1):41-55.

6. Larry J Suva, Robert J Griffin, Issam Makhoul. Mechanisms of bone metastases of breast cancer Endocrine-Related Cancer2009:16:703-713.

7. Lauren A. Kingsley, Pierrick G.J. Fournier, John M. Chirgwin and Theresa A. Guise. Molecular Biology of Bone Metastasis. Mol Cancer Ther October 2007 6;2609

8. O'Hanlon DM, Kerin MJ, Kent P et al. An evaluation of preoperative CA 15-3 measurement in primary breast carcinoma. Br J Cancer 1995; 71(6): 1288-1291.

9. S. Chourin, D. Georgescu, C. Gray, C. Guillemet, et al.Value of CA 15-3 determination in the initial management of breast cancer patients. Annals of Oncology 2009: 20(5)962-964.

10. Daniela Katz MD, Dvora Aharoni MD.Images in clinical medicine: Lytic Lesions in Breast CancerNew England Journal of Medicine; 2004:27:351

11. Hitoshi Tomono, Susumu Fujioka, Kenji Kato, Katue Yoshida, Yuji Nimura. Multiple myeloma mimicking bone metastasis from breast cancer: Report of a case. Surgery TodayDecember 1998, Volume 28, Issue 12, pp 1304-1306

12. 1Hough B, Brufsky A, Lentzsch S. Metastatic breast cancer or multiple myeloma? Camouflage by lytic lesions. J Oncol. 2010; 2010:509530.

\section{AUTHORS:}

1. L. Aruna

2. P. Manimekhala

3. Shajia Rahman

4. M. Lavanya

5. D. Sumanth Kumar

\section{PARTICULARS OF CONTRIBUTORS:}

1. Assistant Professor Department of Pathology, Osmania General Hospital or Osmania Medical College.

2. Associate Professor, Department of Pathology, Osmania General Hospital or Osmania Medical College.

3. Post Graduate, Department of Pathology, Osmania General Hospital or Osmania Medical College.
4. Assistant Professor, Department of Pathology, Osmania General Hospital or Osmania Medical College.

5. Post Graduate, Department of Pathology, Osmania General Hospital or Osmania Medical College.

\section{NAME ADDRESS EMAIL ID OF THE CORRESPONDING AUTHOR:}

Dr.L. Aruna,

B/4, Madhuranagar,

P.O. S.R. Nagar, Hyderabad - 38.

Email-yerramilli.aruna09@gmail.com

Date of Submission: 09/12/2013.

Date of Peer Review: 10/12/2013.

Date of Acceptance: 26/12/2013.

Date of Publishing: 09/01/2014 